\title{
Yo sé, Nosotros podemos, Ellos se cuidan. LA ESCENA DISCURSIVA DEL DEBATE SOBRE LA EDUCACIÓN SEXUAL INTEGRAL *
}

\section{Gabriel Dvoskin**}

\section{Resumen}

En este artículo, analizamos el proceso de configuración de la escena discursiva (Goffman, 1981; Carbó, 1995) desarrollado por la diputada Maffei durante su intervención en el debate parlamentario sobre el proyecto de Educación Sexual Integral, en agosto de 2006, en la Argentina. Las imágenes de los diferentes participantes constituidas en la interacción discursiva nos permite, por un lado, acceder a las valoraciones que se pretenden imponer sobre el signo ideológico "sexualidad" y, por el otro, analizar las operaciones discursivas efectuadas para la relegitimación del campo político y del sujeto político en particular.

Palabras clave: Escena discursiva, dialogismo, valoración, campo político, sexualidad.

\section{KNOW HOW, WE CAN DO IT, THEY TAKE CARE. THE DISCURSIVE SCENE OF THE DEBATE ABOUT THE INTEGRAL SEXUAL EdUCATION}

\begin{abstract}
In this article, we will discuss the configuration process of the discursive scene (Goffman, 1981; Carbó, 1995) developed by the congresswoman Maffei, during her intervention in the parliamentary debate about the Sexual Education project. This debate took place in Argentina in August 2006. The different roles of the participants built in the discursive interaction allow us to, on the one hand, have access to the different values imposed on the ideological sign of "sexuality" and, on the other hand, analyze the discursive operations made to relegitimate the political field and the political subject in particular.
\end{abstract}

Keywords: Discursive scene, dialogism, valuation, politic field, sexuality.

Recibido: 15-11-2013

Aceptado: 20-11-2013

* El presente trabajo forma parte de mi investigación doctoral titulada De eso (no) se habla. Entre lo prohibido y lo impensable de la sexualidad en la educación formal argentina y se desarrolla en el marco del proyecto UBACyT dirigido por Alejandro Raiter y Julia Zullo, "Ser joven no tiene edad: representaciones sociales de los jóvenes en Argentina en los discursos sociales de las últimas décadas".

** Argentino, Licenciado y Profesor en Letras, Doctorando en Lingüística, Universidad de Buenos Aires-C.O.N.I.C.E.T., Buenos Aires, Argentina. gabidvoskin@gmail.com 


\section{Enunciación, dialogismo y valoración}

Los principios propuestos por Saussure (2001) para los estudios sobre el lenguaje dieron lugar a una serie de investigaciones que recortaron el objeto de estudio de modo tal que excluyeron del campo de la lingüística elementos esenciales del lenguaje. La distinción entre lengua y habla, luego retomada parcialmente por Chomsky (1978) en la forma de competencia y actuación, produjo la exclusión de las investigaciones lingüísticas de los hablantes reales y con ellos, de los contextos de producción, circulación y recepción de los enunciados. La lingüística se limitó a trabajar con sujetos ideales y con textos elaborados por el propio analista, y restringió sus estudios a las reglas de buena formación de oraciones, hecho que permitió difundir y consolidar la concepción del lenguaje como un sistema de signos cuya codificación y decodificación sirven meramente a la transmisión de información (Ducrot, 1982), dejando entrever la ilusión de un código único y monolítico.

Sobre la base de esta concepción del lenguaje, la noción de modalidad estuvo sesgada al estudio de la actitud que adopta el hablante (modus) ante lo dicho (dictum) (Bally, 1950; Kovacci, 1992). Esta bipartición separó el carácter subjetivo del mensaje de su contenido semántico proposicional, como dos elementos discretos.

Sin embargo, en los trabajos de Voloshinov (2009) y Bajtín (2005) podemos notar una concepción diferente del lenguaje ya que postulan que es en el proceso de la interacción entre participantes reales, históricamente situado, donde surge el signo lingüístico y, por lo tanto, es allí donde debe estudiarse:

La realidad concreta del lenguaje en cuanto discurso no es el sistema abstracto de formas lingüísticas, ni tampoco una enunciación monológica aislada, ni el acto psicofísico de su realización, sino el acontecimiento social de interacción discursiva, llevada a cabo mediante la enunciación y plasmada en enunciados. La interacción discursiva es, entonces, la realidad principal del lenguaje. (Voloshinov, 2009: 151)

La primacía del aspecto comunicativo de esta perspectiva pone de relieve su carácter inherentemente dialógico y polifónico, al plantear la existencia que subyace al enunciado de un sujeto hablante que se dirige a 
un otro y cuya relación determina la forma de la emisión verbal. Por otro lado, todo enunciado se posiciona de una determinada manera respecto de enunciados anteriores, a los que retoma en el interior del mismo discurso, a la vez que anticipa posibles réplicas, por lo que hace convivir en el propio discurso a una diversidad de voces ante las cuales asume posturas diferentes:

Una actuación discursiva participa en una discusión ideológica a gran escala: responde algo, algo rechaza, algo está afirmando, anticipa las posibles respuestas y refutaciones, busca apoyo, etc. Todo enunciado, por más terminado e importante que fuese en sí mismo, es tan sólo un momento en la comunicación discursiva continua. (Voloshinov, 2009: 152)

El lenguaje no constituye simplemente un instrumento a partir del cual los sujetos se transmiten referencias sobre un mundo que es exterior a él, sino que el discurso se construye como pararrealidad autónoma y suficiente (Raiter, 1999). Esta construcción incluye no sólo las representaciones que circulan sobre el mundo, sino también las imágenes de los sujetos que son constituidos en el proceso discursivo: "Representación de la realidad y forma material de la ideología, factor de poder e interacción argumentativa, juego de identidades y enmascaramientos, el lenguaje es mucho más que 'comunicar ideas.'" (García Negroni \& Zoppi Fontana, 1992: 12).

El estudio del lenguaje no puede separarse de sus condiciones reales de uso. Lenguaje, discurso e ideología conforman un único e indisoluble fenómeno. A partir del Análisis del Discurso es posible, por un lado, acceder al estudio de la construcción social de la realidad y, por el otro, entender de una forma más acabada la especificidad del lenguaje a través de conocer los fundamentos sociales que determinan su actividad.

En este artículo, estudiamos el discurso político parlamentario, para lo que analizamos el debate que tuvo lugar el día 16 de agosto de 2006, en la Argentina, a raíz del proyecto de Educación Sexual Integral. Específicamente, nos centramos en la intervención de la diputada del partido Afirmación de una República Igualitaria (ARI) por Buenos Aires, Marta Olinda Maffei, miembro informante del proyecto y quien estuviera al frente de la Confederación de Trabajadores de la Educación de la República Argentina (CTERA) entre 1995 y 2004. 
Nuestra investigación aborda el proceso de configuración de la escena discursiva desarrollado en su discurso, esto es, qué voces incorpora, a partir de qué mecanismos lingüísticos trae a escena dichas voces, qué imágenes construye de sus destinatarios y de sí misma y cuál es su actitud frente a los diversos posicionamientos discursivos que evoca.

Los recursos empleados por Maffei para traer a escena las distintas voces y posicionamientos discursivos sobre el tema de la educación sexual configura un lugar de enunciación particular, a partir del cual no sólo construye una determinada imagen de sus persona sino también de sus destinatarios. Estas distintas imágenes constituidas en el proceso discursivo contribuyen, por un lado, a la producción y circulación de determinadas valoraciones sobre el signo ideológico "sexualidad" y, por el otro, configuran un determinado dispositivo de enunciación para el sujeto político.

\section{El discurso parlamentario como escena discursiva}

Nuestro trabajo parte de considerar la actividad lingüística como una forma de actuación que pone en juego competencias no sólo de índole gramatical, sino también situacionales, históricas, políticas e ideológicas (Lavandera, 1984). Concebimos el uso del lenguaje como una elaborada puesta en escena (Goffman, 1981; Carbó, 1995) en la que el emisor evoca diferentes voces y posicionamientos discursivos, frente a los cuales establece su propia postura y construye simultáneamente una determinada imagen de sí mismo y de sus interlocutores, imágenes que no están predeterminadas ni son estáticas, sino que se negocian y configuran en el desarrollo de la interacción comunicativa. El uso del lenguaje involucra una determinada actuación del sujeto hablante, dirigida a -y juzgada por- su interlocutor, juego especulativo en el que la imagen de uno constituye la imagen del otro: "Actuación es una dimensión omnipresente del uso del lenguaje porque es una dimensión omnipresente de la evaluación del lenguaje y no hay uso sin evaluación" (Duranti, 2000: 39).

Esta puesta en escena inherente a todo uso del lenguaje se manifiesta de un modo característico en el discurso parlamentario. El Parlamento constituye un escenario en el que sus participantes se presentan en calidad de representantes de los diversos sectores políticos y sociales y sus intervenciones están normadas de forma explícita por el Reglamento 
de la Cámara de Diputados. Además de los legisladores -los diputados, en el caso de nuestro trabajo-, que son los actores centrales en este tipo de evento comunicativo, es de particular importancia la función del presidente de la cámara, quien debe dirigir las discusiones, pero no participa de ellas.

Sumado a estos participantes se encuentra otro destinatario, el ciudadano común que se informa de lo sucedido en el debate, ya sea a través de los canales de televisión que transmiten las sesiones en vivo o de los noticieros que repasan los fragmentos más destacados, o bien a través de las versiones taquigráficas disponibles en la página web del Congreso de la Nación ${ }^{1}$. Este destinatario indirecto (Negroni, 2001), si bien no está presente físicamente en el recinto y no es a él a quien está dirigido explícitamente el mensaje, condiciona la forma en que es construido el enunciado, ya que todos los legisladores conocen de su existencia y lo consideran al tomar la palabra, especialmente en aquellos debates que tratan asuntos de gran repercusión a nivel social, como lo fue el proyecto de ley sobre la Educación Sexual Integral².

En el caso de los debates acerca de un proyecto de ley, se debe buscar el consenso, para lo que los legisladores, además de presentar su voto, lo fundamentan, hecho que los lleva a valerse de estrategias discursivas muy diversas (Pérez, 1999). El Análisis del Discurso se convierte así en una herramienta sumamente provechosa para indagar en las creencias y representaciones que subyacen a estas argumentaciones, así como también en las imágenes que los locutores construyen tanto de sí mismos como de sus destinatarios.

Caracterizamos el debate parlamentario como un tipo de discurso político y, por consiguiente, inherentemente polémico (Verón, 1987), rasgo que coloca en el seno del enunciado al destinatario, sujeto discursivo que no es homogéneo, sino que está desdoblado entre aquél al que se dirige el emisor y aquél otro con el que se enfrenta:

Metafóricamente, podemos decir que todo discurso político está habitado por un Otro negativo. Pero, como todo discurso,

1 www.congreso.gov.ar

2 Una encuesta realizada por el Instituto Social y Político de la Mujer/ISPM y la United Nations Funds for Population/UNFPA, en el año 2004, consultó a 1200 personas de entre 16 y 55 años de edad, en varias jurisdicciones de la Argentina, y dio como resultado que un 96,9\% de los encuestados estaba a favor de incluir la educación sexual en el ámbito escolar. 
el discurso político construye también un Otro positivo, aquél al que el discurso está dirigido. En definitiva, de lo que se trata es de una suerte de desdoblamiento que se sitúa en la destinación. (Verón, 1987: 16)

Esta multidestinación simultánea (García Negroni y Zoppi Fontana, 1992) trae aparejada la necesidad de emplear una serie variada de operaciones discursivas para la constitución de cada uno de los interlocutores, fenómeno que construye especularmente la propia imagen del locutor. El discurso político se presenta así como un espacio privilegiado para estudiar el carácter dialógico y polifónico del lenguaje. La multiplicidad de voces que allí aparecen y la importancia que adquieren las dimensiones del locutor y de sus destinatarios en la elaboración del discurso otorgan a este género un interés primordial para esta clase de investigaciones.

El interés no reside, entonces, únicamente en lo que se dice, en el plano del enunciado, sino principalmente en el plano de la enunciación, en su dimensión ideológica (Verón, 1985), nivel en el que se construyen las imágenes del locutor y de sus destinatarios y en el que se establece la relación que el discurso mantiene con sus condiciones sociales de producción.

Al tomar la palabra Maffei en el debate, los siete diputados preopinantes habían dado su apoyo al proyecto. Debido a la votación en bloque que ya habían manifestado los partidos sobre este tema, la sanción de la ley estuvo garantizada desde un comienzo. Este hecho le permitió a la diputada del ARI desentenderse de los indecisos y centrar su discurso en el aspecto esencialmente polémico de todo debate político: la constitución del contradestinatario, aquel con el que se enfrenta, y del prodestinatario, aquel que comparte las creencias del locutor (Verón, 1987).

El proyecto de Educación Sexual Integral fue presentado primero en la Cámara de Diputados, el día 16 de agosto de 2006, donde obtuvo media sanción, con tan solo un voto en contra, y luego en la Cámara de Senadores, el 4 de octubre del mismo año, donde fue sancionada la ley, también con un solo voto opositor. 


\section{Marco teórico y metodológico}

Nuestro perspectiva de análisis parte de la propuesta teórica esbozada por Bajtín (2005) y Voloshinov (2009), que plantea que todo enunciado es inherentemente dialógico, en el sentido de que en él se inscribe una diversidad de voces (inter)discursivas, cada una de ellas caracterizada por un punto de vista particular y por diferir del resto en sus contenidos ideológicos y axiológicos. Por otro lado, todo enunciado retoma enunciados anteriores, en los que o bien se apoya o bien refuta y reelabora, y, a su vez, anticipa potenciales respuestas, ubicándose, de este modo, en una determinada posición en la esfera dada de la comunicación discursiva:

Todo hablante es de por sí un contestatario, en mayor o menor medida: él no es un primer hablante, quien haya interrumpido por vez primera el eterno silencio del universo, y él no únicamente presupone la existencia del sistema de la lengua que utiliza, sino que cuenta con la presencia de ciertos enunciados anteriores, suyos y ajenos, con los cuales su enunciado determinado establece toda suerte de relaciones (se apoya en ellos, problematiza con ellos, o simplemente los supone conocidos por su oyente). (Bajtín, 2005: 258)

La Teoría de la Polifonía (Ducrot, 2001) profundiza este enfoque al postular la existencia de distintas voces en la constitución de un enunciado, cada una de ellas pertenecientes a sujetos discursivos diferentes, por lo que los responsables de los enunciados y el autor global de la enunciación no necesariamente son el mismo. Esta no correspondencia biunívoca obliga a diferenciar entre el locutor, responsable del enunciado y a quien remiten las marcas del "yo" del discurso, y sus enunciadores, a quienes se atribuye ser los responsables de ciertos actos particulares vinculados con la enunciación.

Por su parte, la Teoría de la Valoración (Martín \& White, 2005) retoma esta perspectiva dialógica y polifónica y propone estudiar la evaluación a partir de la descripción y explicación de los sistemas de opciones semánticas que ofrece el lenguaje para valorar, adoptar posiciones, negociar relaciones, construir personas textuales y presentar posturas ideológicas como naturales. Divide los recursos evaluativos del lenguaje en tres grandes dominios semánticos o subsistemas: la actitud, que incluye los significados a través de los cuales los hablantes 
evalúan positiva o negativamente sus enunciados (ya sea desde un punto de vista emocional, moral o estético); el compromiso, que remite al posicionamiento del emisor respecto de las proposiciones comunicadas en su texto; y la gradación, que se relaciona con la manera en que los hablantes intensifican o disminuyen la fuerza de sus enunciados y gradúan el foco de sus categorizaciones semánticas. Estos tres dominios de significados en modo alguno constituyen regiones discretas y separadas unas de las otras, sino que la valoración en el lenguaje puede operar simultáneamente en varias de ellas.

En este artículo, abordamos el nivel semántico-discursivo con el objeto de analizar la escena discursiva configurada por Maffei. Para ello, tomamos las distinciones formuladas por Ducrot sobre los diferentes sujetos discursivos y las categorías de análisis propuestas por la Teoría de la Valoración. Nos centramos en el análisis del subsistema de compromiso, es decir, en los recursos lingüísticos que se utilizan para posicionar al emisor en relación con las proposiciones comunicadas en su texto y los significados por medio de los cuales se reconocen o ignoran los diversos puntos de vista que los enunciados ponen en juego. A lo largo de una escala de valores, podemos encontrar dos dimensiones contrapuestas: la monoglosia, que ignora la diversidad de voces que entra en escena en todo acto comunicativo; y la heteroglosia, caracterizada por el reconocimiento de posturas alternativas en el propio enunciado, ya sea para su apertura dialógica o para su clausura.

\section{La colonización del campo político}

Los trágicos acontecimientos sucedidos en la Argentina los días 19 y 20 de diciembre de 2001, dejaron al descubierto la desarticulación económica, política y social que caracterizó al país desde la última dictadura militar y que se profundizó durante los gobiernos menemistas (Svampa, 2005).

La dictadura militar argentina tuvo como objetivo llevar a cabo una política de represión, a la vez que aspiraba a refundar las bases materiales de la sociedad. Mediante el terrorismo de Estado, apuntó al exterminio y al disciplinamiento de vastos sectores sociales movilizados. Por otro lado, puso en marcha un programa de reestructuración económica que habría de tener hondas repercusiones en la estructura social y productiva. La lógica de acumulación desencadenada por este proceso apuntó también 
a liquidar las posibilidades de una coalición nacional-popular, al tiempo que fue sentando las bases de un sistema de dominación centrado en los grandes grupos económicos nacionales y los capitales transnacionales.

La primera presidencia de Menem profundizó este modelo al borrar las distancias que existían entre el sistema de poder y el sistema político, lo que dio origen a una etapa marcada por la polarización y la fragmentación social, así como por la hegemonía de los grupos económicos en alianza con el partido mayoritario. El Plan de Convertibilidad, implementado en el año 1991 por el entonces Ministro de Economía, Domingo Cavallo, suprimió los principales mecanismos de control del Estado sobre la economía a favor de las reglas de mercado, liberalizando la inversión extranjera en la Argentina. La adopción de la convertibilidad supuso el abandono de una política monetaria autónoma, hecho que acentuó la dependencia estructural del país frente al mercado internacional y sus sobresaltos coyunturales.

El vaciamiento de las capacidades institucionales del Estado fue una característica de este período, producto de la drástica reconfiguración de las relaciones entre lo público y lo privado. Gran parte de la estrategia de legitimación desarrollada por el nuevo gobierno menemista apuntó entonces a desacreditar el rol monopólico del Estado, augurando que la libertad de mercado aseguraría la eficiencia y la modernización.

La subordinación de la política a la economía condujo a la naturalización de la globalización, legitimando, así, la nueva dependencia. Esta representación contribuyó fuertemente al desdibujamiento de la política como esfera de deliberación y participación, como espacio de disputa y de conflicto. Asu vez, esta reducción potenció la desarticulación entre el mundo de la política institucional y las formas de politización de lo social. Uno de los corolarios de este proceso es que se aceleró la desarticulación de lo político respecto de lo social, y la esfera política se tornó cada vez más autorreferencial, sustrayendo las decisiones políticas incluso al debate parlamentario. La crisis del año 2001 dejó en evidencia los conflictos sociales derivados del modelo de gobierno neoliberal, dejando como resultado más contundente la muerte de treinta y nueve personas, y expuso la desconfianza que los ciudadanos sentían hacia la política y los políticos en especial ${ }^{3}$.

3 La consigna "Que se vayan todos", popularizada en ese momento de la Argentina, es una marca elocuente de esta crisis de legitimación política. 
Si bien en un clima social más calmo, este fue el contexto histórico en el que iniciaría su mandato Néstor Kirchner, en el año 2003. El reestablecimiento de un modelo nacional-popular, consigna proclamada tanto en sus discursos como en los de su sucesora y esposa, Cristina Fernández, debía ser acompañado por una relegitimación del campo político, para lo que serían necesarias medidas que rearticularan los órdenes social, político y económico, así como también exigía de un cambio en la imagen del ser político, sustentado en una transformación del dispositivo de enunciación (Verón, 1985) configurado en el discurso político.

En este orden de fenómenos, podemos identificar la sanción de distintas leyes destinadas a producir cierto marco de igualdad y cohesión social, rasgo característico del modelo nacional-popular (Svampa, 2005), como la sanción de la ley Nacional de Educación, en 2006, que extiende el número de años de educación formal obligatoria a trece, o más cercano en el tiempo, la Asignación Universal por Hijo, sancionada en 2009, que otorga a padres desocupados un beneficio económico por cada hijo menor de dieciocho años de edad.

Incluso la sexualidad, práctica ligada al ámbito privado, pasó a formar parte de la agenda política. En el año 2002, se sancionó la ley Nacional de Salud Sexual y Reproductiva, que determina la responsabilidad del Estado de garantizar el derecho universal a la información en materia sexual y, en el año 2006, la ley de Educación Sexual Integral, que establece la obligatoriedad de la enseñanza de educación sexual en todas las escuelas del país, tanto de gestión estatal como privada, desde el nivel Inicial hasta el Superior de Formación Docente y de Educación Técnica no Universitaria. En relación con este tema, también se sancionaron las leyes de Matrimonio Igualitario, en 2010, que otorga la posibilidad a personas del mismo sexo de contraer matrimonio, y de Identidad de Género, en 2012, que permite que las personas trans (travestis, transexuales y transgéneros) sean inscriptas en sus documentos personales con el nombre y el sexo de elección, y ordena que todos los tratamientos médicos de adecuación a la expresión de género sean prestados por el Estado Nacional.

A partir del análisis de la ley de Educación Sexual Integral intentamos, por un lado, acceder a las valoraciones que se pretenden imponer sobre el signo ideológico "sexualidad", lo que contribuye a analizar si este 
proyecto de educación sexual representa un discurso emergente en relación al eje de referencias impuesto por el discurso dominante (Raiter, 2003) que califica este signo con valores represivos (Foucault, 2001; Freud, 2000).

Por otro lado, el estudio de los mecanismos de enunciación nos sirve para entender las relaciones del discurso con sus condiciones de producción, por lo que es en este nivel donde podremos analizar las operaciones discursivas efectuadas para la relegitimación del campo político y del sujeto político en particular, operación necesaria en el marco de un proyecto que pretende la rearticulación del orden político y social.

\section{La escenificación discursiva}

El carácter esencialmente dialógico de todo enunciado se manifiesta de un modo particular en el discurso político, debido a que este tipo de discursos coloca en el centro de la escena al destinatario. Su particularidad reside en el hecho de que no sólo se dirige a un otro a quien pretende persuadir, característica que lo asemejaría al discurso de la publicidad, sino que también constituye un interlocutor con el que se enfrenta y polemiza, configurándolo como adversario del propio discurso (Verón, 1987).

El análisis de los diferentes destinatarios constituidos en el proceso discursivo permite dar cuenta no sólo de las imágenes de estos, sino también de las que el locutor construye de su propia persona en la interacción, configurando, de ese modo, el dispositivo de enunciación.

\subsection{Nosotros podemos: creencias compartidas}

Uno de los rasgos característicos del discurso político está dado por la constitución de un destinatario que comparte las mismas creencias del emisor y con quien este último conforma un colectivo de identificación, expresado a través de un "Nosotros inclusivo" (Verón, 1987). Es a este destinatario a quien van dirigidas las informaciones consideradas ya conocidas e incuestionables y que permiten definir el marco de creencias del que parte el hablante para elaborar su argumentación. La identificación de este destinatario permite dar cuenta no sólo del grupo en el que se incluye el locutor, hecho que contribuye a construir una determinada imagen de su persona, sino también de los valores y conocimientos que establece como socialmente válidos y compartidos. 
Las aseveraciones monoglósicas y los presupuestos de los enunciados son construcciones gramaticales que ignoran la diversidad de voces que se ponen en juego en todo acto comunicativo (Kaplan, 2004), por lo que presentan la información transmitida como una verdad obvia, general. Esta característica las convierte en formas privilegiadas para imponer un determinado marco discursivo, por lo que su análisis es sumamente provechoso para acceder a las creencias y representaciones que subyacen y conforman el trasfondo sobre el que se erige el discurso.

Los presupuestos de un enunciado tienen la particularidad de introducir los contenidos que vehiculizan "como una evidencia, como un marco incuestionable adonde debe inscribirse necesariamente la conversación, como un elemento del universo del discurso." (Ducrot, 2001: 34). La información presupuesta se presenta, así, como constitutiva del diálogo mismo. Este tipo de construcciones puede identificarse mediante las pruebas de la interrogación o la negación, que consisten en transformar los enunciados en una pregunta o en una negación y verificar qué información permanece siendo transmitida. Los contenidos que perduran constituyen presupuestos del enunciado.

En el discurso de Maffei, podemos reconocer varias emisiones que contienen información presupuesta:

23. "En este recinto estamos a punto de empezar a desmitificar algunos temas y de correrle el velo al tabú de la educación sexual, que ha causado estragos en la historia de la civilización y particularmente en la historia de las mujeres y de las niñas. Es la primera vez que vamos a correr el velo del currículo oculto que ha existido por siglos dentro del sistema educativo."

24. "Todos conocemos las consecuencias de haber ocultado la educación sexual. Todos sabemos -y los docentes lo hemos visto mucho más- lo que han padecido nuestros chicos. Conocemos acerca del abuso y de la violencia, de la prostitución y pornografía infantiles en la actualidad, de las enfermedades de transmisión sexual, de la maternidad adolescente [...] y de los conflictos familiares ocultos." (12)

4 Todos los ejemplos corresponden a la transcripción taquigráfica tomada de la reunión ordinaria $\mathrm{N}^{\circ} 26$, sesión $\mathrm{N}^{\circ} 19$ del 16 de agosto de 2006, disponible en http:/ / wwwl.hcdn.gov.ar. En adelante, sólo colocaremos los números de página entre paréntesis. 
En estos dos fragmentos, encontramos, por un lado, el uso reiterado de la primera persona del plural. Sin embargo, podemos observar que su alcance no es el mismo en ambos casos, sino que se pueden distinguir dos colectivos diferentes. En el primero, es indudable que ese Nosotros remite al conjunto de los diputados que apoyan el proyecto de ley. En cambio, en el segundo enunciado, la referencia ya no es la misma, sino que aparece un nuevo grupo, el de los docentes, en el que Maffei también se incluye.

Esta doble definición de un colectivo de identificación va configurando la imagen de ese otro al que se dirige positivamente y, paralelamente, la suya: al posicionarse como diputada y docente, su poder de acción se amplía, lo que le atribuye un papel especial en el proyecto de educación sexual integral.

Por otro lado, en estos fragmentos discursivos reconocemos los siguientes presupuestos:

a. Existen temas que han sido mitificados.

b. La educación sexual constituye un tema tabú.

c. El carácter tabú de la educación sexual ha causado estragos en la historia de la civilización y en particular, en la historia de las mujeres y niñas.

d. El sistema educativo tiene un currículo oculto.

e. Los chicos tienen padecimientos.

f. Existe abuso sexual, violencia, prostitución y pornografía infantiles, enfermedades de transmisión sexual y conflictos familiares que alguien ha ocultado.

A su vez, en este discurso, encontramos otro tipo de construcciones que si bien no tienen la forma del presupuesto, sí presentan la información como la única opción posible, ignorando cualquier tipo de alternativa y, así, asumen para sí una pretensión de verdad incuestionable:

25. “iCuántos siglos de violencia, cuántos miedos, cuántas culpas!"

26. "Es enorme la cantidad de denuncias [sobre abuso sexual] de la Sociedad Argentina de Pediatría. No hay límite de edad. Las víctimas son cada vez de menor edad." (12) 
Tanto en el primer tipo de enunciados como en el segundo, la información que se presenta como parte del universo de creencias de los interlocutores se relaciona exclusivamente con los males ocasionados por la sexualidad, particularmente en las mujeres y las niñas. El abuso sexual, la prostitución infantil, las enfermedades venéreas o los sufrimientos son los temas que la diputada recupera como punto de partida para desarrollar su postura a favor de la educación sexual en los colegios. La promoción del proyecto se fundamenta, principalmente, sobre la base de los males que su no tratamiento ha traído aparejados, por lo que su aplicación es comparable con una especie de remedio o cura para una enfermedad que acecha.

El empleo de enunciados monoglósicos y de construcciones que contienen información presupuesta define un marco discursivo que constituye a ese Nosotros al que pertenece la locutora y al que se dirige positivamente.

\subsection{La negación de los otros: la dimensión polémica}

Todo discurso político constituye en el centro de la escena a un destinatario a quien se le atribuye la opinión contraria a la del emisor, el contradestinatario (Verón, 1987), hecho que implica enfrentamiento, debate, polémica. En el discurso de Maffei, esta figura discursiva se identifica principalmente con los diputados opositores a la sanción del proyecto, interlocutores presentes físicamente en el Congreso. Sin embargo, también puede reconocerse en este sujeto discursivo a los padres, aunque de manera secundaria. Estas voces opositoras son recuperadas por Maffei con el objeto de enfrentarlas para luego refutarlas.

Uno de los principales recursos a partir de los cuales se realiza esta operación es a través del uso de la negación metalingüística, caracterizada por "descalificar el marco o espacio de discurso impuesto por una palabra anterior [...] y por declarar situarse entonces en un espacio discursivo diferente del rechazado o descalificado." (García Negroni, 2001: 209):

27. "Ya es tiempo de actuar y educar no sólo a la víctima. También hay que educar la voluntad, la sensibilidad, la ética y la pasión del posible victimario."

28. "Ir a la escuela no es un hecho relacionado con la posibilidad de confirmar o rechazar las opiniones de los familiares, acentuar la discrecionalidad de 
los docentes o soportar la de quien fuere. Uno va a la escuela a aprender, a insertarse en una cultura y a adquirir los conocimientos socialmente valiosos para ser una persona integra." (13)

Ambos enunciados tienen el mismo valor exclusivo sustitutivo que el coordinante "Sino": "El segundo constituyente se contrapone al precedente y lo excluye, sustituyéndolo" (Kovacci 1986: 192). La afirmación que subyace al primer elemento negado proviene de aquellas voces que Maffei posiciona en contra de la educación sexual integral, mientras que el segundo elemento incorpora una segunda voz, la propia de la emisora, que reemplaza y corrige a la primera.

El uso de la negación metalingüística le permite a Maffei operar la crítica sobre el estado actual de la situación y plantear la necesidad de un cambio. Este doble procedimiento le sirve para, por un lado, presentar la urgencia de la educación sexual en los colegios y, por el otro, cuestionar a aquellos que se oponen a la medida.

Del mismo modo, el uso de preguntas retóricas es otro de los recursos empleados en este discurso para negar posturas alternativas al proyecto de educación sexual:

29. "[El programa de educación sexual] Estará presente cuando se curse Psicología, Filosofía, Historia, Biología, Literatura. ¿Qué van a hacer los padres? ¿Van a retirar a sus hijos de todas las clases? Cada vez que un maestro empiece a hablar racionalmente de un problema sexual durante cualquier asignatura, ¿Van a sacar al chico? ¿Le van a dar un permiso automático para que se retire de clase cada vez que se toque un tema de educación sexual?" (13)

Este tipo de preguntas resultan absurdas, hecho que genera la imposibilidad de contestar afirmativamente a alguna de ellas sin ser clasificado como ridículo. Este efecto se acentúa aún más al calificar las clases de educación sexual como racionales, categorización que conduce a inferir que quienes se oponen a ellas son, cuanto menos, no racionales.

Por último, encontramos que la refutación de posturas alternativas también se realiza mediante el recurso del distanciamiento, a partir del cual la locutora presenta la proposición como perteneciente a una voz externa y manifiesta su desacuerdo frente ella (Martin \& White, 2005). 
30. "Se dice que en este proyecto de ley existe [...] la posibilidad de una objeción de conciencia. En este sentido, quiero establecer dos aspectos básicos, porque me parece que existe confusión." (13)

31. "Los mismos padres que dicen que podrían objetar el derecho de su hijo de aprender en forma sistemática, científica, ética y ordenada dentro de la escuela a través de los especialistas y de los docentes, no pueden inhibir lo que después ocurre fuera de clase." (13)

El uso del verbo 'decir', en ambos enunciados, comporta una presuposición factiva negativa sobre lo dicho (Kerbrat-Orecchioni, 1986), lo que marca el distanciamiento de la diputada respecto de la proposición comunicada. Este posicionamiento se hace explícito al enunciar la "confusión", en el primer caso, o al denunciar la incapacidad de los padres para educar a sus hijos, en el segundo.

Este enfrentamiento se percibe claramente al analizar el carácter anticipatorio del discurso de Maffei, esto es, cómo se posiciona frente a eventuales respuestas futuras:

32. "No se puede seguir desgajando al ser humano, no se puede seguir fracturándolo, y muchísimo menos se puede recortar, a partir de nuestras incapacidades, miedos, inhibiciones y desconocimientos que tenemos, el derecho de los pibes a aprender." (11)

En este fragmento, aparece el recurso de la refutación a partir del uso reiterado de la negación polémica, que "opone el punto de vista de dos enunciadores antagónicos [y] permite conservar las presuposiciones del enunciado positivo subyacente" (García Negroni, 2001: 205-206). Estas dos posturas antagónicas serían la de Maffei, que plantea la necesidad de un cambio, y la de un otro a quien se le atribuye la forma positiva subyacente, esto es, que la educación sexual integral no es necesaria y que se puede continuar con los mismos métodos de enseñanza que se han practicado hasta el momento. Este recurso le permite a la diputada no sólo plantear la necesidad de un cambio en la educación y, simultáneamente, cuestionar su estado actual, sino también adelantar las consecuencias negativas que traería aparejadas la no implementación de esta medida, consecuencias que ya forman parte de la situación actual:

33. "Si no educamos a las dos partes [a la víctima y al victimario], volverán a reiterarse las prácticas del abuso sexual." (12) 
La negación polémica no cuestiona el marco discursivo previo sino que, por el contrario, lo consolida al erigir la postura del hablante sobre la base de los males ocasionados por la falta de educación integral. A su vez, funciona como una estrategia para criticar a todo aquel que no apoye el proyecto al colocarlo en el rol de cómplice de estos males o peor aún, como su causante, ya sea de manera implícita o, como en la cita siguiente, absolutamente explícita:

34. "La mayoría de los que se oponen a la educación sexual terminan siendo los que en la casa realizan el abuso sexual." (12)

Por otra parte, vemos que el recurso del pronunciamiento, que señala el fuerte involucramiento del emisor con respecto al punto de vista que emite (Martin \& White, 2005), sirve a la caracterización del proyecto como la solución a estos males:

35. "Es la primera vez que vamos a correr el velo del currículo oculto que ha existido por siglos dentro del sistema educativo y quizás por primera vez podamos empezar a hablar justificadamente de educación integral. Por primera vez vamos a sacarnos el "mascarón", vamos a sacarnos la hipocresía y vamos a empezar a plantear una historia diferente, de hablar con la verdad, sin dejar la ética, los principios y la verdad de lado." (11)

El énfasis en la proclamación de su postura se manifiesta en la reiteración del sintagma "por primera vez", que indica la idea de cambio y de ruptura frente a un pasado atroz. Esta novedad radica en "correr el velo del currículo oculto", en "sacarnos la hipocresía", en definitiva, en "hablar con la verdad". La educación sexual integral viene a imponer "La verdad" de la sexualidad, otra verdad, pero diferente de la anterior.

La constitución del contradestinatario funciona como una estrategia retórica a partir de la cual Maffei polariza el debate entre los que apoyan y promueven el proyecto y aquellos otros que se posicionan en contra. Esta polarización no es en modo alguno ingenuo ni inocente: la postura contraria al proyecto es fuertemente criticada, atribuyendo a quienes la sostienen el rol de cómplices y/o causantes directos de los males ocasionados por las prácticas sexuales. Este lugar en la escena discursiva construida por Maffei es atribuido a los diputados opositores, personaje inherente a todo debate parlamentario, y los padres, quienes al ser contrapuestos en el orden sintagmático a los docentes, como se muestra en el ejemplo 32, quedan descalificados en la tarea de educar a los jóvenes en materia sexual. 


\subsection{Yo sé: la relegitimación del campo político}

Todo discurso no sólo construye las imágenes de sus destinatarios, también activa una determinada representación del emisor. Esta imagen es el producto de distintos aspectos que se ponen en escena sobre el sujeto enunciador en el proceso comunicativo: "El ethos de un discurso resulta de una interacción entre diversos factores: ethos prediscursivo, ethos discursivo (ethos mostrado), pero también los fragmentos del texto donde el enunciador evoca su propia enunciación (ethos dicho)." (Maingueneau, 2010: 207).

En el corpus analizado, observamos que a lo largo de su discurso, Maffei adopta diferentes posiciones de enunciación, estrategia que le permite exhibir distintas características de su persona. En primer lugar, su voz está autorizada para manifestarse debido a su condición de diputada, estatus que se ve reafirmado en su discurso no sólo por la inclusión de su persona dentro de este colectivo, sino también por sus conocimientos de las leyes y de los derechos de las personas:

36. "El derecho de los padres no puede llegar a inhibir el derecho de los chicos a recibir educación e información sexual. [...] Éste es un derecho consagrado en la ley, en la Constitución y en todos los tratados internacionales que ha firmado la República Argentina y en los cuales se basa aquella ley." (13)

Es su papel como diputada el que la habilita a tomar la palabra y el que le otorga un rol preponderante en la sanción del proyecto. Sin embargo, en el transcurso de su intervención despliega otra faceta: su imagen como docente:

37. "Debo decir algo que la práctica docente me ha enseñado reiteradamente. La mayoría de los que se oponen a la educación sexual terminan siendo los que en la casa realizan el abuso sexual. Esto lo hemos visto reiteradamente en la escuela pública." (12)

$\mathrm{Su}$ experiencia como docente le otorga un lugar distintivo en el debate sobre la educación sexual. No habla sólo porque puede sino también porque sabe. Este conocimiento lo ha adquirido de forma directa mediante sus propias vivencias, la fuente más confiable para acceder al conocimiento (Chafe, 1986). Es su labor como docente la que le ha proporcionado estos conocimientos. 
En cambio, su condición de mujer, característica evidente, no se presenta como una cualidad relevante de la imagen que construye de su persona:

38. “ Cuántos años y cuántos siglos de ocultamiento, que han cargado de culpa, vergüenza y miedo a las personas, al punto de que en muchísimos casos, aun como adultas, no han podido tener una relación saludable en materia sexual y de relaciones interpersonales!"

La víctima de la falta de la educación sexual, primordialmente la mujer, se construye como objeto discursivo: de ellas se habla, pero no se las incorpora en la escena discursiva bajo ninguna de las distintas categorías de destinatario. Este distanciamiento le garantiza a Maffei no ser confundida con una posible víctima, papel que podría quitarle objetividad en el tratamiento del tema, hecho que le haría perder credibilidad.

Configura, así, su imagen de especialista en materia sexual, característica que se manifiesta también en el tono didáctico que atraviesa la mayor parte de su discurso, fenómeno vinculado típicamente con el saber. La recurrencia de descripciones, explicaciones y correcciones sobre temas relacionados con el campo de la sexualidad construye un espacio diferencial de enunciación producto del saber que solo ella posee:

39. "La situación sexual no aclarada y la violencia padecida han terminado siendo la base de una reiteración patológica donde la víctima pasa a ser victimario, repitiéndose asi históricamente los procesos de abuso sexual." (12)

40."El 68 por ciento de todas las violencias proviene del ámbito familiar, el ámbito más intimo, el de las personas que deberían cuidar a los niños; incluso, en la escuela, en las instituciones deportivas". (12)

41. ¿Por qué se trata de un derecho que está por encima de la voluntad de los padres? Porque en realidad ir a la escuela y educarse es un derecho para que las personas tengan defensa propia; un derecho social para que tengan oportunidad de defenderse. Ir a la escuela no es un hecho relacionado con la posibilidad de confirmar o rechazar las opiniones de los familiares, acentuar la discrecionalidad de los docentes o soportar la de quien fuere. Uno va a la escuela a aprender, a insertarse en una cultura y a adquirir los conocimientos socialmente valiosos para ser una persona integra". (13) 
Tanto el primer como el segundo enunciado describen estados de hechos particulares y establecen una lectura del pasado y de la situación actual. Su formulación mediante aseveraciones monoglósicas presenta las proposiciones como supuestamente objetivas y, por lo tanto, incuestionables, hecho que contribuye a presentar al locutor como una autoridad en la materia. El tercer fragmento, en cambio, no sólo describe, también corrige y explica, incorporando un conjunto diverso de voces que rápidamente es reducido a una sola, heteroglosia efímera en la medida en que es precisamente el rechazo de estas otras voces lo que justifica su inclusión.

Más allá de estos papeles que desempeña, de diputada y docente, especialista en problemáticas sobre sexualidad, en su discurso se muestra otra característica de su persona que la hace especial en el recinto del Congreso de la Nación. Ya su condición de docente la aleja del resto de los diputados, en su mayoría abogados, pero es su imagen de persona honesta la que la presenta como un ser distinto en el terreno de la política. Esta cualidad se construye a través del empleo de un registro coloquial, comprensible, "transparente", metáfora evidente de la honestidad:

42. "Por primera vez vamos a sacarnos el 'mascarón'". (11)

43. "Saquémonos la careta y empecemos a hablar seriamente de los verdaderos trastornos que padecen nuestros pibes." (12)

"Mascarón", "Careta" o "Pibes" son términos inadecuados para este tipo de prácticas discursivas. Este registro contribuye a mostrar a la diputada como una persona comprometida con el tema, preocupada por los jóvenes y, fundamentalmente, dispuesta a decir "la verdad". Esta puesta en escena (re)legitima su lugar de enunciación y resignifica el campo político al construir una nueva imagen del ser político.

\section{Entre el decir y el mostrar}

En este artículo, analizamos la escena discursiva configurada por Maffei en su discurso pronunciado durante el debate parlamentario sobre el Proyecto de Educación Sexual Integral. A partir de caracterizar las imágenes que constituye de sus destinatarios y de su persona y de analizar su postura frente a los diferentes posicionamientos discursivos que evoca, pretendimos dar cuenta de las valoraciones sobre el signo "sexualidad" que circulan en su discurso y de las transformaciones 
operadas en el discurso político como parte del proceso de resignificación de este campo.

En un primer momento, nos interesamos por la figura del prodestinatario, para lo que analizamos los enunciados monoglósicos y aquellas construcciones que contienen información presupuesta, debido a que ambos tipos de emisiones ignoran cualquier alternativa posible, presentando los hechos como verdades obvias. Este sujeto discursivo está desdoblado entre los diputados que apoyan el proyecto y los docentes, ambos colectivos en los que se incluye la locutora. La configuración de este interlocutor le sirve a Maffei para describir el estado actual de la problemática sexual en la Argentina producto de la falta de educación formal sobre este tema. Notamos en esta descripción una reducción del tema a los males no deseados de las prácticas sexuales, como los embarazos no oportunos ${ }^{5}$, las transmisiones de enfermedades o los casos de abusos. Este conocimiento lo fundamenta en su experiencia como docente, función que la distingue de la mayoría de los diputados.

Esta diferenciación en cuanto a los lugares de saber se hace aún más notoria al constituir a su contradestinatario, papel atribuido a los diputados opositores a la sanción del proyecto y a los padres. Esta operación se realiza a través de diferentes recursos, que tienen como finalidad la descalificación de la postura opositora. El uso de la negación metalingüística, de preguntas retóricas o de construcciones que contienen presuposiciones factivas negativas coloca a este destinatario en el lugar del error o de la ignorancia, característica que deslegitima su opinión, a la vez que consolida el lugar de la locutora.

El tono descriptivo y didáctico que predomina en el discurso, eminentemente monoglósico, construye un lugar de enunciación que diferencia a la locutora de sus destinatarios, tanto de a los que se dirige positivamente como a los que confronta.

El saber como fundamento de legitimación reconfigura el lugar de enunciación política al construir una imagen diferente del sujeto político: no es simplemente la condición de diputada la que la habilita a hablar, sino

5 El 17 de mayo de 2013, se realizó el $8^{\circ}$ Congreso Argentino de Salud Integral del Adolescente, en el que se organizó una mesa redonda sobre el "Embarazo no oportuno", sintagma que refiere a aquellas gestaciones ocurridas sin mediar planificación y en contextos desfavorables y, de ese modo, se omiten (o se engloban) los complementos "no deseado", "no planificado" o "adolescente". 
fundamentalmente su conocimiento en el tema a debatir. Se academiza el lenguaje político. La figura carismática propia de la política argentina de los años 90 es ahora reemplazada por la del especialista, estrategia al servicio de la puesta en aceptabilidad inherente a todo discurso político (Raiter, 1999).

Esta posición de enunciación asumida por Maffei como especialista transforma la sexualidad en objeto de conocimiento y como tal, el tema queda sometido a criterios de verdad. Esta operación reproduce una economía restrictiva respecto de quiénes están autorizados para hablar, quiénes deben limitarse a escuchar y quiénes quedan excluidos de la escena.

El pecado original adquiere ahora la forma del error, cuya corrección, basada en la indisolubilidad entre el sexo, el amor y la monogamia (Giddens, 1998) y justificada a partir de cuestiones de salud, no es ingenua ni gratuita: "En la base de la legitimación sigue habiendo una ética; ello es posible porque el derecho formal per definitionem, al delimitar un ámbito de acciones legales, deslinda un ámbito complementario de acciones morales." (Habermas, 1973: 152). La figura del experto reintroduce una verticalidad en el tratamiento de la sexualidad que contradice la idea de integralidad propuesta en el proyecto, reduciendo el tema a la mera genitalidad, particularmente a la prevención de las consecuencias no deseadas. La cientifización de la sexualidad lleva incorporadas reglas de conducta, pautas de comportamiento. En otras palabras, formas de control social. 


\section{Referencias bibliográficas}

Bally, Charles. (1950). Linguistique générale et linguistique française. Berna: Francke.

Bajtin, Mijaíl. (2005). Estética de la creación verbal. México: Siglo XXI.

Carbó, Teresa. (1995). El discurso parlamentario mexicano entre 1920 y 1950. Un estudio de caso en metodología de análisis del discurso. México: Centro de Investigaciones y Estudios Superiores en Antropología Social.

Chafe, Wallace. (1986). Evidentiality: the linguistic coding of epistemology. New Jersey: Norwood.

Chomsky, Noam. (1978). Estructura sintácticas. México: Siglo XXI.

Ducrot, Oswald. (1982). Decir y no decir. Barcelona: Anagrama. . (2001). El decir y lo dicho. Buenos Aires: Edicial.

Duranti, Alessandro. (2000). Antropología lingüística. Madrid: Cambridge University Press.

Foucault, Michel. (2001). Historia de la sexualidad. La voluntad del saber. Argentina: Siglo XXI.

Freud, Sigmund. (2000). El malestar en la cultura, Madrid: Amorrortu Editores.

García Negroni, M. M. y M. Zoppi Fontana. (1992). Análisis lingüístico y discurso político. El poder de enunciar. Buenos Aires: Centro Editor de América Latina.

García Negroni, María Marta. (2001). La enunciación en la lengua. Madrid: Gredos.

Giddens, Anthony. (1998). La transformación de la intimidad. Buenos Aires: Cátedra.

Goffman, Ervin. (1981). Formas of Talk. Filadelfia: Pennsylvania University Press.

Habermas, Jürgen. (1973). Problemas de legitimación en el capitalismo tardio. Madrid: Cátedra.

Kerbrat-Orrecchioni, Catherine. (1986). La enunciación de la subjetividad en la lengua. Buenos Aires: Hachette. 
Kaplan, Nora. (2004). Nuevos desarrollos en el estudio de la evaluación en el lenguaje: la teoría de la valoración. Boletín de Lingüística, 22, 52-78.

Kovacci, Ofelia. (1986). Las construcciones con sino y no...pero, y los campos léxicos. Estudios de Gramática española. Buenos Aires: Hachette. (1992). El comentario gramatical. Madrid: Arco.

Lavandera, Beatriz. (1984). El cambio de modo como estrategia de discurso. Variación y significado. Buenos Aires: Hachette.

Maingueneau, Dominique. (2010). El enunciador encarnado. Revista Versión, 24, 203-225.

Martín, J.R. y P. R. R. White. (2005). The language of evaluation. Appraisal in English. Londres: Palgrave.

Pérez, Sara. (1999). Voces en el Parlamento. En Raiter A. (comp.) Discurso y ciencia social. Buenos Aires: Eudeba.

Raiter, Alejandro. (1999). Transformaciones discursivas en el discurso político. Lingüística y Política. Buenos Aires: Biblos. . (2003). Lenguaje y Sentido Común. Buenos Aires: Biblos.

Saussure, Ferdinand de. (2001). Curso de Lingüística General. Buenos Aires: Losada.

Svampa, Maristella. (2005). La sociedad excluyente. Buenos Aires: Taurus. Verón, E. \& S. Sigal. (1985). Perón o muerte. Los fundamentos discursivos del fenómeno peronista. Buenos Aires: Hispanomérica. . (1987). La palabra adversativa. El discurso político. Lenguaje y acontecimientos. Buenos Aires: Hachette.

Voloshinov, Valentin. (2009). El marxismo y la filosofía del lenguaje. Argentina: Godot. 